\title{
Relations of the Low-Level Extratropical Cyclones in the Southeast Pacific and South Atlantic to the Atlantic Multidecadal Oscillation
}

\author{
MARY TOSHIE KAYANO AND MARCELO BARbio RoSA \\ Centro de Previsão de Tempo e Estudos Climáticos, Instituto Nacional de Pesquisas Espaciais, São José dos \\ Campos, São Paulo, Brazil \\ VADLAMUDI BRAHAMANANDA RAO \\ Centro de Previsão de Tempo e Estudos Climáticos, Instituto Nacional de Pesquisas Espaciais, São José dos Campos, \\ São Paulo, Brazil, and Department of Meteorology and Oceanography, Andhra University, Visakhapatnam, India \\ Rita Valéria Andreoli and Rodrigo Augusto Ferreira de Souza \\ Escola Superior de Tecnologia, Universidade do Estado do Amazonas, Manaus, Amazonas, Brazil
}

(Manuscript received 29 August 2018, in final form 8 April 2019)

\begin{abstract}
The relations of the low-level extratropical cyclones in the southeastern Pacific and South Atlantic with the sea surface temperature (SST) anomalies associated with the Atlantic multidecadal oscillation (AMO) during the summer and winter of the 1979-93 cold AMO (CAMO) and 2003-17 warm AMO (WAMO) are analyzed. During both seasons and in both AMO phases, the cyclone trajectories defined by cyclone local counts exceeding 10 events per grid box occur approximately in the areas with the AMO-related positive SST anomalies. The cyclone densities in most latitudes during both seasons are higher in the CAMO than in the WAMO. Thus, the cyclone density in the study domain presents a reduction trend during the 1979-2017 period. The large-scale northward SST anomalous gradients between the bands north and south of $40^{\circ} \mathrm{S}$ increase the long-wave baroclinicity in the midlatitudes in the WAMO, and the southward SST anomalous gradients decrease it in the CAMO. Consequently, the short-wave baroclinicity is higher in the WAMO than in the CAMO in the southeastern Pacific midlatitudes. Thus, the cyclones are more energetic in the WAMO than in the CAMO. In the South Atlantic region off the Argentinean coast, both the barotropic and baroclinic conversion terms are positive, indicating an increase of the kinetic energy of the short waves. The low-level cyclones in the southeastern Pacific and South Atlantic are modulated by the AMO. As far as we know, the relation of the SH low-level extratropical cyclones to the AMO documented here was not studied before.
\end{abstract}

\section{Introduction}

Migratory cyclones are important parts of the general circulation in transporting heat, momentum, and moisture between the equator and the poles (Peixoto and Oort 1992) and in driving weather and climate. Using automatic tracking schemes, several authors analyzed the climatological features of the Southern Hemisphere (SH) mean sea level extratropical cyclones and their trends and variability (Jones and Simmonds 1993; Sinclair 1994, 1995, 1997; Simmonds and Keay 2000a; Mendes et al. 2010; Eichler and Gottschalck 2013; Neu

Corresponding author: Mary Toshie Kayano, mary.kayano@ inpe.br et al. 2013; Wang et al. 2013; Reboita et al. 2015; Grieger et al. 2018). These studies indicated that the cyclone climatological features depend on the dataset, period of analysis, and tracking method used.

Wang et al. (2013) identified these systems in the SH using the National Oceanic and Atmospheric Administration (NOAA) Twentieth Century Reanalysis (NOAA-20CR) data during the 1871-2010 period, and showed trends in the cyclone activity index that vary with the seasons and regions. During winter, they found increases in this index in the circumpolar latitudes of the South Atlantic and Indian Ocean, and decreases in southern Australia, in the circumpolar latitudes of the South Pacific, and in the region to the southeast of South America. During summer, they registered increases in 
the cyclone activity index in the South Atlantic, eastern South Pacific, and around the circumpolar latitudes, and decreases in the Indian Ocean and western South Pacific. Neu et al. (2013) showed that different algorithms give similar patterns of the number of cyclones in the extratropics of both hemispheres, in particular the strong events. Grieger et al. (2018) confirm this result for the SH events. Nevertheless, both studies recommended caution with respect to the total cyclone counts when only one method is used.

Befort et al. (2016) compared the long-term trends of extratropical cyclones during the 1901-30,1931-60, and 1961-90 periods using two reanalysis datasets: NOAA-20CR and European Centre for Medium-Range Weather Forecasts (ECMWF) Twentieth Century Reanalysis (ERA-20C). In the SH, they registered large differences between the datasets. In the NOAA-20CR, they found an increase in the cyclone activity in all regions, except the Pacific by 1970 and a decrease afterward, and an increase in the number of extreme cyclones from 1920 to 2000. In the ERA-20C, they found an increase in the cyclone activity over the twentieth century, with a local maximum in the number of extreme cyclones by 1940 and two local minima, one by the beginning of the twentieth century and the other by 1960 . Another aspect raised by Schneider and Fogt (2018) concerns the spurious pressure decrease trends in the $60^{\circ}-90^{\circ} \mathrm{S}$ band during the 1905-2010 period in the NOAA-20CR, ERA-20C, and ECMWF's Coupled Ocean-Atmosphere Twentieth Century Reanalysis (CERA-20C), which reflect the number of assimilated observations. All these results indicate that the trends in the cyclone activity in the $\mathrm{SH}$ should be taken with care.

On the other hand, Simmonds and Keay (2000a) documented a variability of the $\mathrm{SH}$ extratropical cyclones using the 6-hourly National Centers for Environmental Prediction (NCEP)-National Center for Atmospheric Research (NCAR) reanalysis during the 1958-97 period. They found an increase in the annual average number of cyclones in the entire $\mathrm{SH}$ and in the $30^{\circ}-70^{\circ} \mathrm{S}$ band from the beginning of the period up to a maximum that occurred, respectively, in 1972 and 1970. They associated the decrease trend after these years with the SH warming, and argued that the lowfrequency variability of the number of these systems might be related to the decadal and multidecadal sea surface temperature (SST) variability in the SH. In this context, several authors registered a decadal variability of the SST in the outflow regions of the western boundary currents in the $\mathrm{SH}$, which coincide with those dominated by the midlatitude westerlies (Parker et al. 1994; Venegas et al. 1996, 1998; Reason 2000). Using a general atmospheric circulation model, Reason and
Murray (2001) provided indications that the SH extratropical cyclones are affected by the underlying SST variations in a decadal time scale. With a warming forcing over the entire $\mathrm{SH}$ midlatitudes and 21-yr integrations, they obtained a large-scale trough in the midlatitudes and a ridge in the higher latitudes, which lead to increases in the baroclinicity and the cyclone density in the $40^{\circ}-55^{\circ} \mathrm{S}$ band and decreases to the south of this band.

Reason and Murray's (2001) work concerned the SST decadal variability in the $\mathrm{SH}$ midlatitudes noted previously in a number of papers (Venegas et al. 1996, 1998). However, persistent SST anomalies in the extratropical Southern Ocean also occur in longer time scales. One phenomenon that might cause such anomalies is the well-known large-scale multidecadal climate variability mode whose main action center is located in the North Atlantic, the so-called Atlantic multidecadal oscillation (AMO) (e.g., Enfield et al. 2001; Kerr 2000). Schlesinger and Ramankutty (1994) identified the AMO signal as a 65-80-yr-period oscillation in the spectrum analysis of the surface air temperature time series of the North Atlantic. Later, several authors showed that the AMOrelated SST anomaly pattern features same-signed anomalies in most of the North Atlantic (Enfield and Mestas-Nuñez 1999; Enfield et al. 2001; Goldenberg et al. 2001; Mestas-Nuñez and Enfield 2001) and opposite-signed SST anomalies in large extensions of the extratropical southern oceans (Folland et al. 1999; Timmermann et al. 2007). The AMO is related to thermohaline circulation changes varying from decadal to multidecadal time scales (Kerr 2000; Delworth and Mann 2000; Knight et al. 2006), with a clear signature in the SST field in the Weddell Sea, as shown in a modeling study by Crowley and Kim (1993). The warm AMO (WAMO) phase features anomalously warmed North Atlantic and anomalously cooled South Atlantic and South Pacific Oceans, and the cold AMO (CAMO) shows an almost-reversed-sign SST anomaly pattern. The AMO-related SST anomaly pattern in the extratropical oceans might impact the baroclinicity and consequently the low-level extratropical cyclones. Studies regarding this issue have been done for the Northern Hemisphere systems (Gómara et al. 2016; Varino et al. 2018). As far as we know, similar studies for SH low-level extratropical cyclones have not yet been done.

Another important aspect that has received little attention concerns the energetics of SH low-level extratropical cyclones, in particular in the southeastern Pacific and South Atlantic region. Few studies can be found on this issue in the literature, in particular concerning the South American neighboring regions (Orlanski 
and Katzfey 1991; Gan and Rao 1999; Pinto and Rocha 2011; Rosa et al. 2013). So this aspect is dealt in the present analysis.

Here, the SH low-level extratropical cyclones during two AMO phases are investigated by focusing on the number of cyclones per grid box and the related energetics in the southeastern Pacific and South Atlantic regions. Analyses are done for two 15-yr periods, 1979 93 for the CAMO phase and 2003-17 for the WAMO phase, which do not include years when the AMO phase changed. Section 2 presents a brief description of the data and methodology. Section 3 presents the differences between the two selected periods for the low-level extratropical cyclones concerning their trajectories and the associated patterns of the kinetic energy, available potential energy, and the barotropic and baroclinic conversion terms of the Lorenz energy cycle. Conclusions are drawn in section 4.

\section{Data and methodology}

Thirty-nine years (1979-2017) of 6-hourly air temperature $T$, vertical pressure velocity $\omega$, geopotential height $Z$, and zonal and meridional winds $u$ and $v$, respectively, from the NCEP-DOE Reanalysis II dataset developed by Kanamitsu et al. (2002) were used here (https://www.esrl.noaa.gov/psd/data/gridded/data.ncep. reanalysis $2 . \mathrm{html}$ ). These data at a $2.5^{\circ}$ horizontal grid resolution and at standard levels from 1000 to $25 \mathrm{hPa}$ were obtained over the $\mathrm{SH}$ poleward of $20^{\circ} \mathrm{S}$.

The SST dataset used here is independent from those used in the NCEP-DOE Reanalysis II, which are global ice and SST from the Hadley Centre for the period from December 1978 to November 1981 and since then the optimum interpolation SST. Here, we used the monthly mean SST data in a $2^{\circ}$ horizontal grid from the extended reconstructed SST version V5 data (https://www.esrl.noaa. gov/psd/data/gridded/data.noaa.ersst.v5.html) for the 1870-2017 period (Huang et al. 2015). These data were used to support the hypothesis that the SST anomaly patterns for the two selected periods contain the AMO-related features. In this case, first the time series in each grid point is detrended in order to remove the climate change effects. The monthly anomalies were based on the 1979-2017 period. Then, the summer and winter SST anomaly patterns of the 1979-93 and 200317 periods were obtained.

The AMO index was obtained from the NOAA website (https://www.esrl.noaa.gov/psd/data/timeseries/AMO/). In addition, the Pacific decadal oscillation (PDO) index was extracted from the Joint Institute for the Study of the Atmosphere and Ocean (JISAO) website (http:// research.jisao.washington.edu/pdo/).
The Lorenz energy cycle of high-frequency disturbances was analyzed. Similar to Blackmon's (1976) analysis, we used a Fourier harmonic longitudinal decomposition over the entire globe instead of time filtering, and the first five modes added to the zonal means were considered as the long waves $l$, and the complementary modes as the short waves $h$. The energy cycle equations after Gan and Rao (1999) are given by the following:

$$
\begin{aligned}
P_{h}= & g^{-1} \int \frac{T_{h}^{2}}{2 \sigma} d p, \\
K_{h}= & g^{-1} \int \frac{u_{h}^{2}+v_{h}^{2}}{2} d p, \\
\frac{\partial K_{h}}{\partial t}= & P_{h} K_{h}+K_{l} K_{h}+R K_{h}, \\
\frac{\partial P_{h}}{\partial t}= & P_{l} P_{h}-P_{h} K_{h}+R P_{h}, \\
P_{l} P_{h}= & -g^{-1} \int \sigma^{-1}\left(u_{h} T_{h} \frac{\partial T_{l}}{\partial x}+v_{h} T_{h} \frac{\partial T_{l}}{\partial Y}\right) d p, \\
K_{l} K_{h}= & -g^{-1} \int\left(u_{h} u_{h} \frac{\partial u_{l}}{\partial x}+u_{h} v_{h} \frac{\partial u_{l}}{\partial y}\right. \\
& \left.+v_{h} u_{h} \frac{\partial v_{l}}{\partial x}+v_{h} v_{h} \frac{\partial v_{l}}{\partial y}\right) d p, \\
P_{h} K_{h}= & -g^{-1} \int \frac{R}{p} \omega_{h} T_{h} d p,
\end{aligned}
$$

where $P$ and $K$ are the available potential energy and kinetic energy, respectively. The other parameters are the gravitational acceleration $g\left(\mathrm{~m} \mathrm{~s}^{-2}\right)$, air temperature $T(K)$, zonal and meridional wind components $\left(\mathrm{m} \mathrm{s}^{-1}\right)$ $u$ and $v$, respectively, vertical pressure velocity $\omega$ (hPa s${ }^{-1}$ ), the ideal gas constant $R$, and the static stability parameter $\sigma\left[=\left(T_{l} / c_{p}\right)-(p / R)\left(\partial T_{l} / \partial p\right)\right]$. For the baroclinic conversion term in this cycle, the available potential energy of the long waves is converted into the potential energy of the short waves $\left(P_{l} P_{h}\right)$, which, in turn, is converted into the kinetic energy of short waves $\left(P_{h} K_{h}\right)$. Therefore, we analyzed here the summation $\left(P_{l} P_{h}+P_{h} K_{h}\right)$, which is called the baroclinic conversion term. For the barotropic conversion term $\left(K_{l} K_{h}\right)$, a positive value represents the conversion of the kinetic energy of the long waves into the kinetic energy of the short waves. Since the interest here is the low-level extratropical cyclones, only these two energy conversion terms were analyzed.

Using the horizontal winds, the relative vorticity at $925 \mathrm{hPa}$ was obtained. Using these data and the automatic tracking scheme developed by Hodges (1994), cyclones at $925 \mathrm{hPa}$ were identified in the study domain, 
which is the band between $75^{\circ}$ and $20^{\circ} \mathrm{S}$ that extends eastward from $160^{\circ} \mathrm{W}$ to the Greenwich meridian. This band encompasses highly populated areas of South America where the low-level extratropical cyclones might have strong impacts. Cyclones with a minimum lifetime of $72 \mathrm{~h}$ were identified when the relative vorticity was less than $-3.0 \times 10^{-5} \mathrm{~s}^{-1}$. Cyclones within the grid box with $0.5^{\circ}$ in latitude and longitude were counted. Cyclones that remained stationary in a grid box were counted only once. This tracking method provides the trajectories of the cyclones.

To focus on the variable patterns associated with the cyclone occurrences, for each grid point we selected the time steps with cyclone occurrences within an area with a $1000-\mathrm{km}$ ray from the grid point. This ray is in accordance with the typical dimension of $2000 \mathrm{~km}$ for a baroclinic wave (Orlanski 1975). Cyclones out of this area were not considered for the time averages. Then, the variables were averaged over these time steps during austral summer [December-February (DJF)] and winter [June-August (JJA)] in the 1979-93 and 2003-17 periods. These averages were obtained for the shortwave kinetic energy, short-wave available potential energy, and baroclinic and barotropic conversion terms.

\section{Results}

\section{a. SST mean state}

Figure 1 shows the summer and winter SST anomaly maps during the two selected periods. The seasonal maps during the 2003-17 period show dominantly positive anomalies in the North Atlantic and negative ones in the $40^{\circ}-70^{\circ} \mathrm{S}$ band, and those during the 1979-93 period show reversed-sign patterns, which are typical in the WAMO and CAMO, respectively (Enfield and Mestas-Nuñez 1999; Folland et al. 1999; Mestas-Nuñez and Enfield 2001; Enfield et al. 2001; Timmermann et al. 2007). These patterns illustrate large-scale meridional SST anomalous gradients between the bands north and south of $40^{\circ} \mathrm{S}$, which are northward directed in the WAMO and southward directed in the CAMO. In the Atlantic, the meridional SST anomalous gradient relates to thermohaline circulation changes varying from decadal to multidecadal time scales (Kerr 2000; Delworth and Mann 2000; Knight et al. 2006). Also, the PDO signature is apparent. The negative SST anomalies in the central North Pacific and the positive ones in the eastern tropical Pacific noted during both seasons in the 1979-93 period are indicative of the warm PDO (WPDO) phase, and the reversed-sign anomaly patterns during both seasons in the 2003-17 period, of the cold PDO (CPDO) phase (Mantua et al. 1997; Zhang et al. 1997). Nevertheless, the
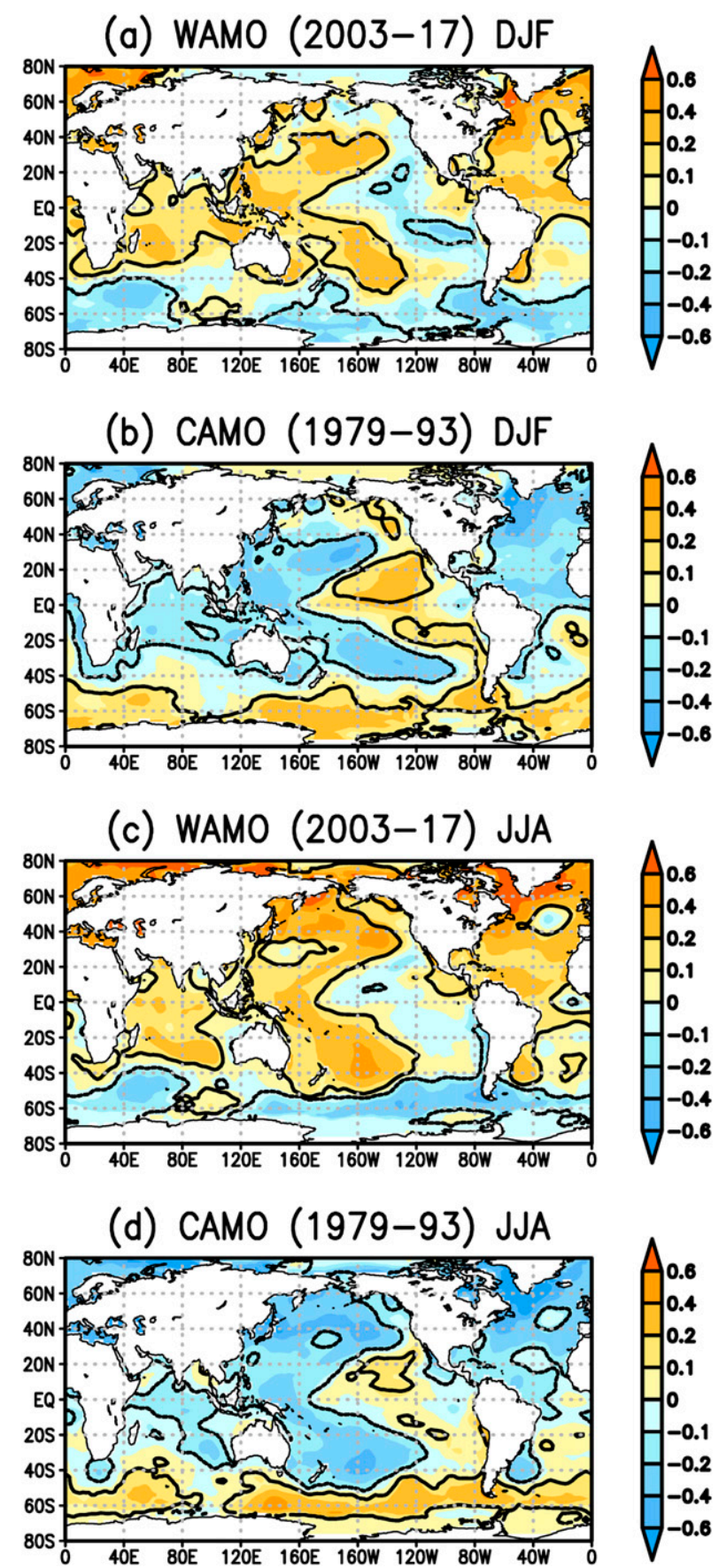

FIG. 1. Seasonal SST anomaly patterns $\left({ }^{\circ} \mathrm{C}\right)$ during summer in the (a) WAMO and (b) CAMO and during winter in the (c) WAMO and (d) CAMO. The continuous (dashed) line encompasses positive (negative) significant values at the $95 \%$ confidence level using the Student's $t$ test. The zero line was omitted.

anomalies in the eastern tropical Pacific are considerably weak in particular during the 2003-17 period.

Therefore, both PDO phases might occur in this period. The annual $\mathrm{AMO}$ and $\mathrm{PDO}$ indices during the 


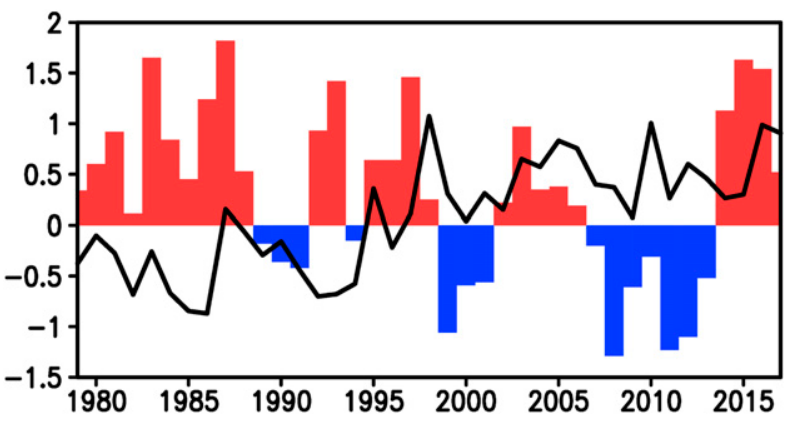

FIG. 2. Annual PDO index (positive values: red; negative values: blue) and AMO index (black line) during the 1979-2017 period.

1979-2017 period are illustrated in Fig. 2. The AMO index is predominantly negative and the PDO index positive during the 1979-93 period. While the AMO index is predominantly positive during the $2003-17$ period, the PDO index oscillates between positive (200306 and 2014-17; WPDO) and negative (2008-13; CPDO) values. Since the AMO remains in the same phase during the 2003-17 period, if the PDO has a strong effect in the SST of the southern middle and high latitudes, the SST patterns in these latitudes must present distinct features during the WPDO and CPDO. However, the SST anomaly patterns in the middle and high latitudes during the WPDO and CPDO do not show substantial differences (Fig. 3). Therefore, the SST anomaly mean states presented in Fig. 1 can be considered to be related to the AMO.

Therefore, the significant negative anomalies in the Drake Passage, the southeastern Pacific, and the South Atlantic during both seasons in the 2003-17 period are indeed part of a large-scale WAMO-related SST anomaly pattern (Figs. 1a,c). The opposite-signed SST anomaly patterns during both seasons in the 1979-93 period are related to the CAMO (Figs. 1b,d). In general, the SST anomaly patterns feature nearly zonal structures along the southern midlatitudes, with strong meridional gradients in the South Atlantic and southeastern Pacific. The east-west SST gradients are also apparent in some cases, as between the Bellingshausen and Amundsen Seas during summer in the WAMO. But the east-west SST gradients are less pronounced than the meridional gradients. During both seasons, the northward SST anomalous gradient increases the baroclinicity in the midlatitudes in the WAMO, and the southward SST anomalous gradient decreases the baroclinicity in these latitudes in the CAMO. Since this analysis refers to the low-frequency SST variations, we can infer that the SST meridional gradients alter the longwave baroclinicity, which in turn takes part in the energy cycle. Therefore, the selected periods show (a)

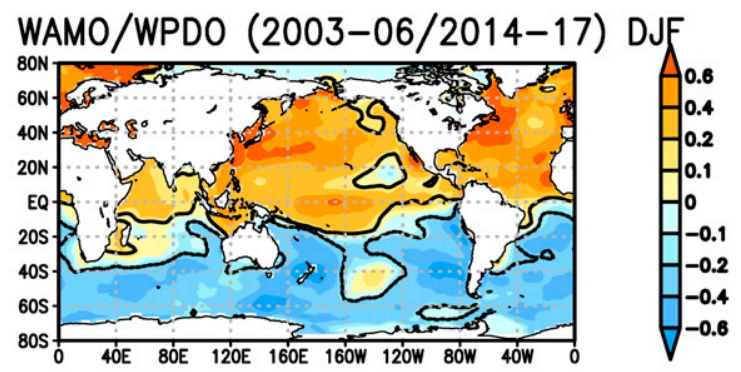

(b) WAMO/CPDO (2007-13) DJF
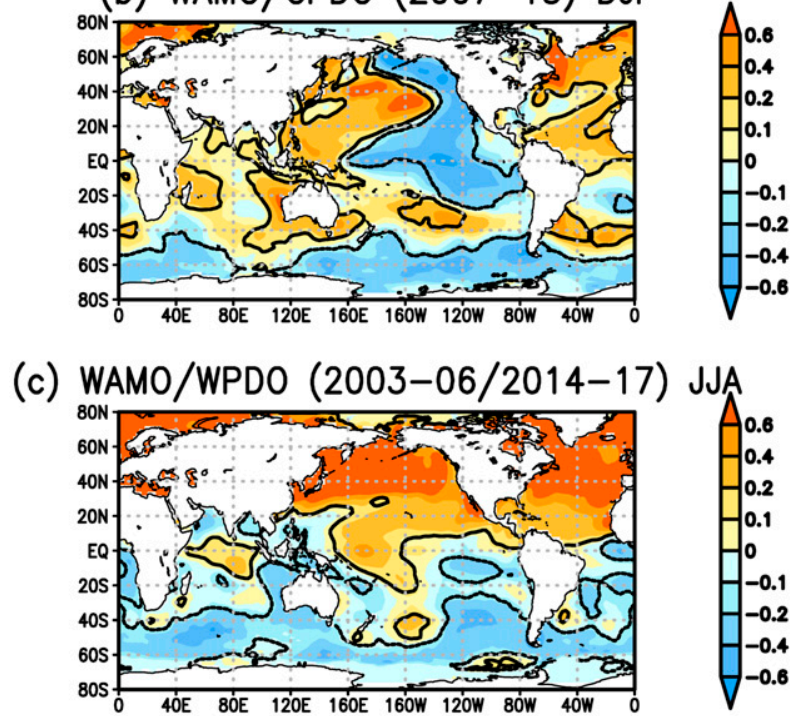

(d) WAMO/CPDO (2007-13) JJA
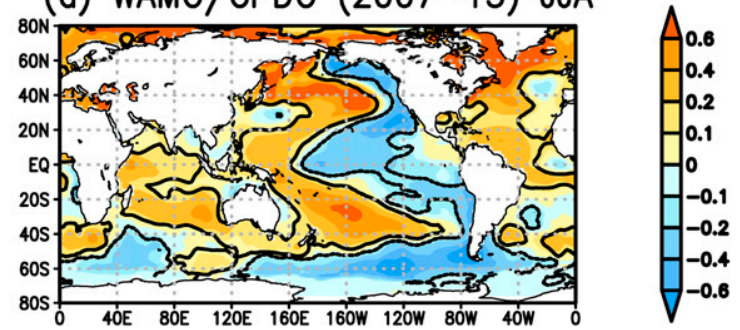

FIG. 3. As in Fig. 1, but during summer in the (a) WAMO and WPDO and (b) WAMO and CPDO and during winter in the (c) WAMO and WPDO and (d) WAMO and CPDO.

contrasting SST mean states under which the cyclones might present distinct features. These differences are analyzed in the next subsections considering only the time steps with the extratropical cyclone occurrences.

\section{b. Extratropical cyclones}

The seasonal maps with the number of cyclones at $925 \mathrm{hPa}$ per grid box in the study domain are depicted in Fig. 4. The cyclone trajectories vary seasonally and with the AMO phases. During summer in the WAMO, the cyclone local counts exceeding 10 events per grid box 


\section{(a) WAMO DJF}

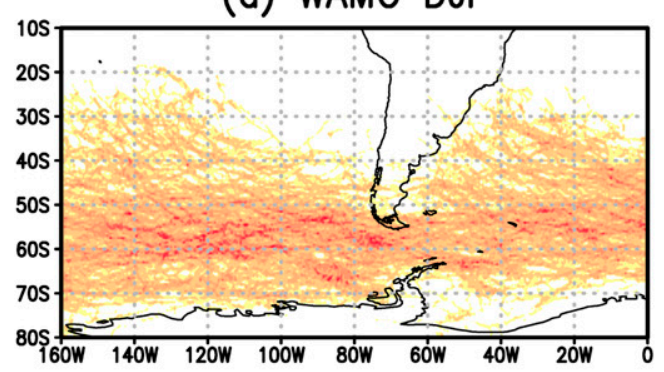

(b) CAMO DJF

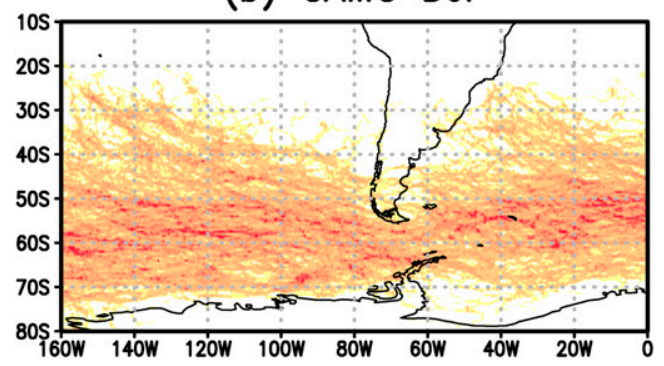

(c) WAMO JJA

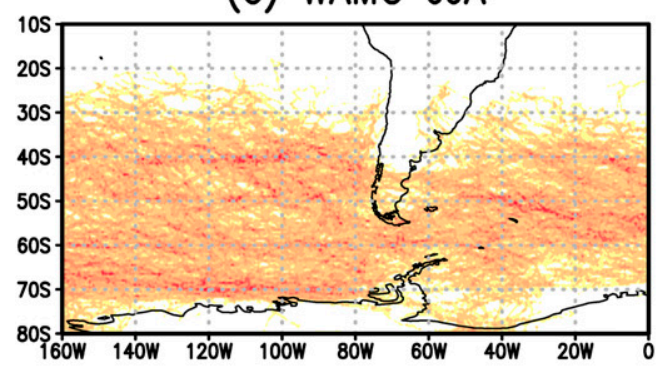

(d) CAMO JJA

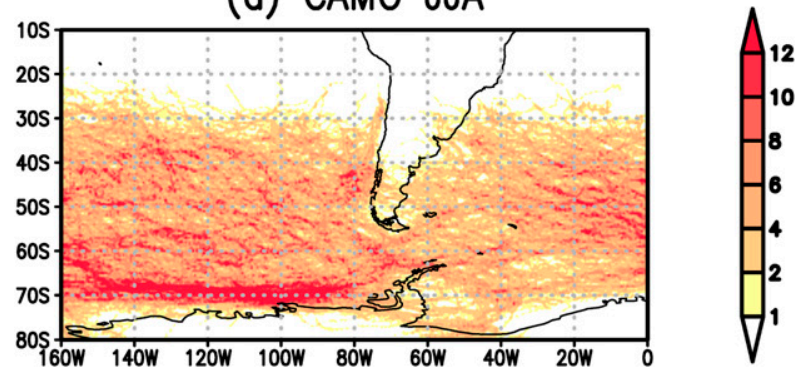

FIG. 4. Number of the 925 -hPa cyclones during summer in the (a) WAMO and (b) CAMO and during winter in the (c) WAMO and (d) CAMO.

occur mostly in the $50^{\circ}-60^{\circ} \mathrm{S}$ band between $150^{\circ}$ and $100^{\circ} \mathrm{W}$, where they turn southeastward along two preferred narrow bands, one of which extends across the Drake Passage and then to the South Atlantic in the $50^{\circ}-$ $60^{\circ} \mathrm{S}$ band (Fig. 4a). Along the high midlatitudes, the number of grid boxes with cyclone local counts exceeding 10 events is lower in the South Atlantic than in the southeastern Pacific (Fig. 4a). Thus, the cyclones in the southeastern Pacific might last longer or be slower than those crossing the South Atlantic. One reason for the distinct behavior of the cyclones in these two oceanic sectors is the SST background along the high midlatitudes, which is anomalously more negative in the Drake Passage and South Atlantic than in the southeastern Pacific (Fig. 1a).

During summer in the CAMO, the cyclone local counts exceeding 10 events appear along narrow zonal areas in the $50^{\circ}-70^{\circ} \mathrm{S}$ band in the southeastern Pacific and along the Drake Passage and in the $50^{\circ}-60^{\circ} \mathrm{S}$ band in the South Atlantic (Fig. 4b). In this case, the largest cyclone local counts are channeled along the $50^{\circ}-70^{\circ} \mathrm{S}$ band, where positive SST anomaly background prevails (Fig. 1b). During summer in the CAMO, the number of grid boxes with cyclone local counts exceeding 10 events is higher than during summer in the WAMO along the high midlatitudes (Figs. 4a,b). This is due to the positive summer SST anomaly mean state in these latitudes in the CAMO and the negative one in the WAMO (Figs. 1a,b and 4a,b).

During winter, the cyclone local counts exceeding 10 events per grid box are spread in a larger latitudinal band mostly between $35^{\circ}$ and $75^{\circ} \mathrm{S}$ for both AMO phases (Figs. 4c and 4d). During winter in the WAMO, the largest cyclone local counts exceeding 10 events per grid box occur along $40^{\circ} \mathrm{S}$ in the southeast Pacific and along $50^{\circ} \mathrm{S}$ in the South Atlantic approximately over the regions with positive SST anomaly mean state (Figs. 1c and $4 \mathrm{c})$. In the case of winter in the CAMO the most prominent feature is the maximum cyclone local counts along $68^{\circ} \mathrm{S}$ in the Bellingshausen Sea, which is a preferred cyclolytic region (Simmonds and Keay 2000b) (Fig. 4d). So a larger number of cyclones remain in this region leading to the maximum cyclone local counts. This maximum is also consistent with the positive SST anomaly mean state in the circumpolar and high middle latitudes in the southeastern Pacific (Figs. 1d and 4d).

The cyclone densities in most latitudes during both seasons in the CAMO surpass those in the WAMO (Fig. 5). Furthermore, the cyclone densities in most latitudes in both AMO phases are higher during winter than during summer, except in the $50^{\circ}-57^{\circ} \mathrm{S}$ band. This occurs due to the larger meridional temperature gradients during winter than during summer (figure not shown). During summer, the largest cyclone densities occur in the $50^{\circ}-60^{\circ} \mathrm{S}$ band, with a maximum of approximately 6 cyclones in the CAMO and 5.5 cyclones in the WAMO (Fig. 5a). On the other hand, during winter, the cyclone densities show several maxima, reflecting the largest counts per grid box along narrow zonal bands (Figs. 4c, 4d, and 5b). A winter maximum occurs around 
(a) DJF

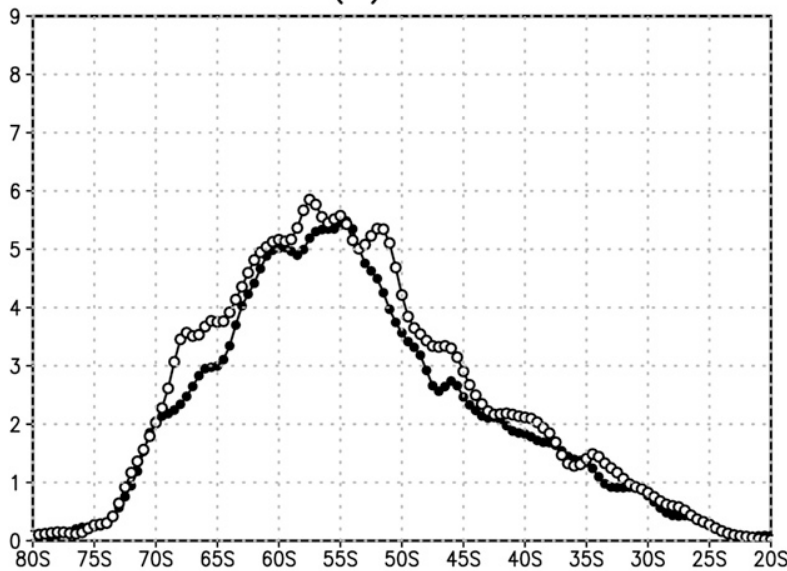

(b) JJA

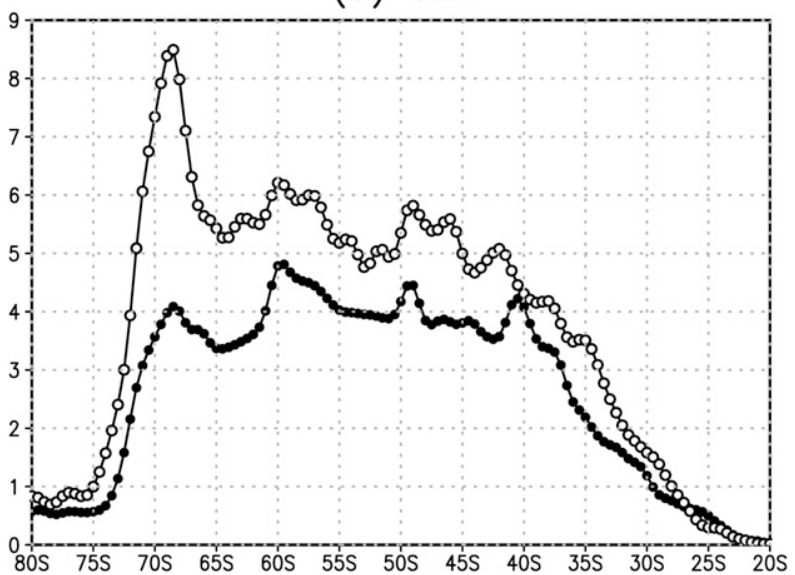

FIG. 5. Density of 925-hPa cyclones in the longitudinal band between $160^{\circ} \mathrm{W}$ and $0^{\circ}$ during (a) summer and (b) winter in the CAMO (open) and WAMO (closed).

$68^{\circ} \mathrm{S}$ for both AMO phases, with the main peak with 8.5 cyclones per grid box in the CAMO and the secondary one with 4 cyclones per grid box in the WAMO. The winter graphs show other peaks, around $60^{\circ}, 48^{\circ}$, and $42^{\circ}-$ $40^{\circ} \mathrm{S}$, which are consistent with the spatial distribution of the cyclone counts (Figs. 4c, 4d, and 5b).

\section{c. Available potential and kinetic energies}

The summer and winter maps of the $P_{h}$ and $K_{h}$ in each AMO phase are illustrated in Figs. 6 and 7. The highest $P_{h}$ values occur in the midlatitudes with a maximum in central northwestern Argentina during summer and in the low midlatitudes and subtropics during winter with a maximum in central Argentina and Uruguay, and the lowest $P_{h}$ values in the southern extratropical latitudes (Fig. 6). These bands with the largest $P_{h}$ values are approximately $10^{\circ}$ north of the corresponding oceanic high midlatitude bands with the largest cyclone local counts (a) WAMO DJF $(\mathrm{Ph})$
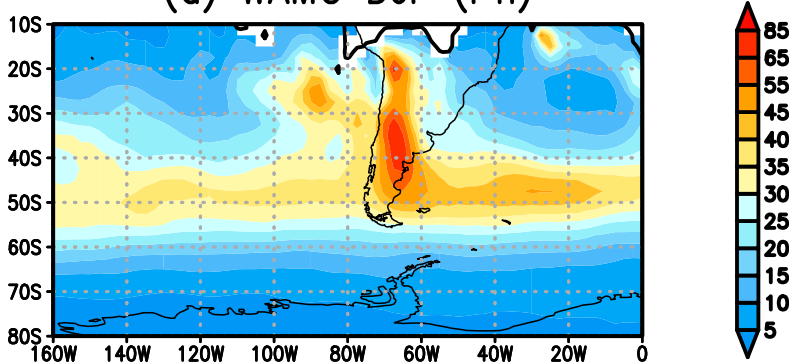

(b) CAMO DJF (Ph)

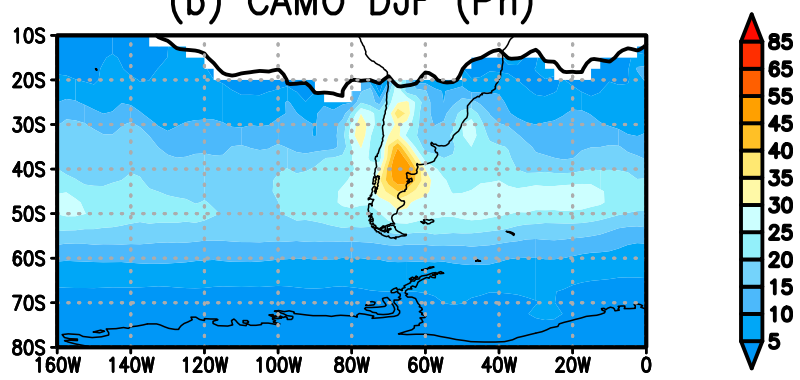

(c) WAMO JJA (Ph)

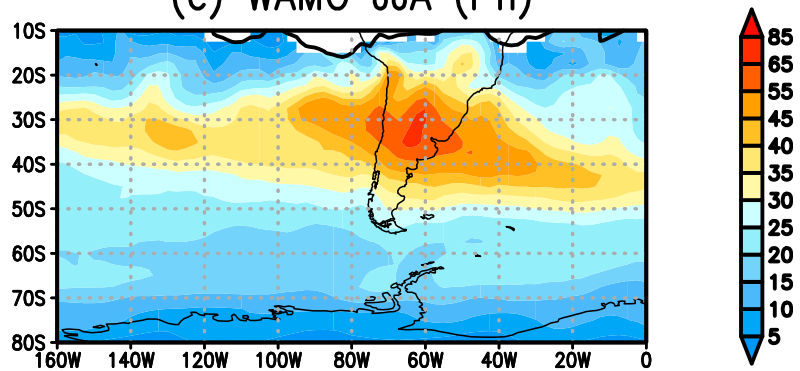

(d) CAMO JJA (Ph)

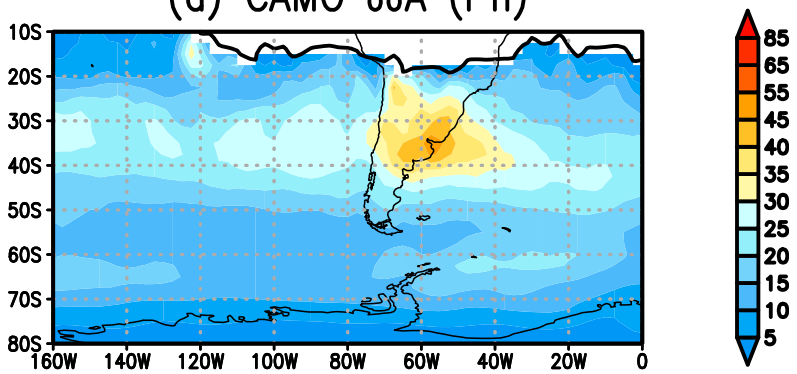

FIG. 6. Available potential energy patterns $\left(1 \times 10 \mathrm{~kJ} \mathrm{~m}^{-2}\right)$ during summer in the (a) WAMO and (b) CAMO and during winter in the (c) WAMO and (d) CAMO.

in the southeastern Pacific and southwestern Atlantic (Figs. 4 and 6). During both seasons, the $P_{h}$ values in the WAMO exceed those in the CAMO over the study domain (figure not shown). Thus, concerning the available potential energy, this result indicates that the cyclones during both seasons are more energetic in the WAMO than in the CAMO (Fig. 6). 
(a) WAMO DJF (Kh)

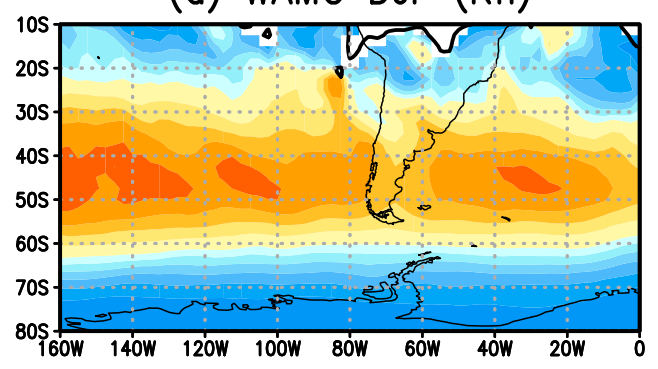

(b) CAMO DJF (Kh)

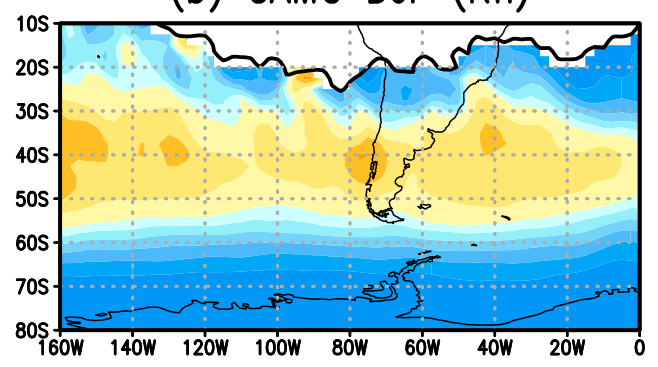

(c) WAMO JJA (Kh)

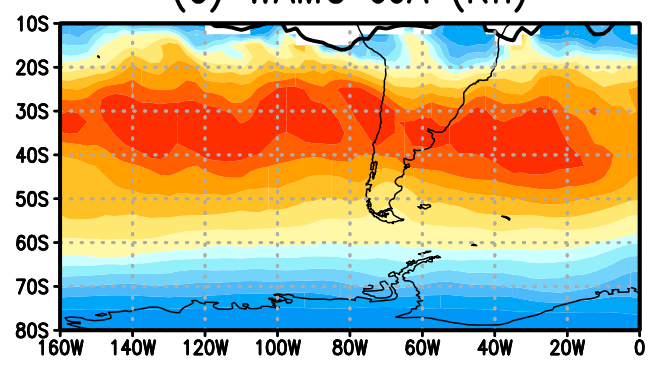

(d) CAMO JJA (Kh)

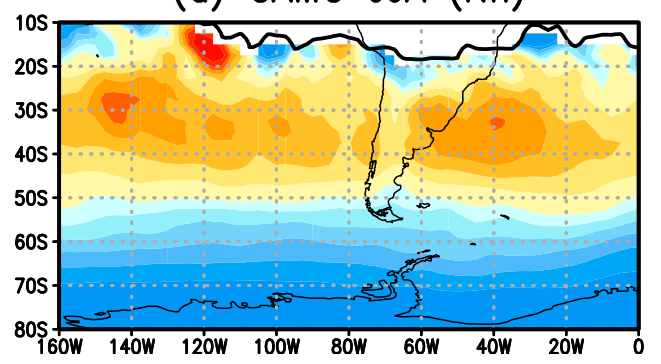

FIG. 7. Kinetic energy patterns $\left(1 \times 10 \mathrm{~kJ} \mathrm{~m}^{-2}\right)$ during summer in the (a) WAMO and (b) CAMO and during winter in the (c) WAMO and (d) CAMO.

In both AMO phases, the highest $K_{h}$ values occur along the $30^{\circ}-50^{\circ}$ and $20^{\circ}-50^{\circ} \mathrm{S}$ bands, respectively during summer and winter, and the lowest ones occur along the southern high latitudes during both seasons (Fig. 7). The bands with the largest $K_{h}$ are $10^{\circ}-20^{\circ}$ north of the high midlatitude bands with the largest cyclone local counts in the southeastern Pacific and southwestern Atlantic (Figs. 4 and 7). Furthermore, the maximum $K_{h}$ values in the southwest Atlantic off the eastern coast of Argentina, Uruguay, and southern Brazil coincide with a previously documented cyclogenetic region (Sinclair 1995, 1997). During both seasons, the $K_{h}$ estimates in the study domain in the WAMO surpass those in the CAMO. Thus, the considerably more energetic low-level cyclones in the study domain might lead to higher energy conversion terms in the WAMO than in the CAMO.

\section{d. Baroclinic and barotropic energy conversion}

During both seasons in both AMO phases, significant positive $P_{l} P_{h}+P_{h} K_{h}$ (baroclinic conversion term) values are found in most of the study domain, except in small areas of the subtropics (Fig. 8). The largest $P_{l} P_{h}+P_{h} K_{h}$ values during summer are found in the $30^{\circ}-60^{\circ} \mathrm{S}$ band, and during winter in the $25^{\circ}-50^{\circ} \mathrm{S}$ band, in particular in the southwestern Atlantic, where the largest $P_{h}$ and $K_{h}$ values are noted (Figs. 6-8). The southwestern Atlantic is a known cyclogenetic area (Sinclair 1995, 1997). The bands with the largest $P_{l} P_{h}+P_{h} K_{h}$ are approximately $10^{\circ}$ north of the corresponding midlatitude bands with the largest cyclone local counts in the southeastern Pacific and southwestern Atlantic (Figs. 4 and 8). During both seasons, larger $P_{l} P_{h}+$ $P_{h} K_{h}$ values occur in the WAMO rather than in the CAMO. Thus, the cyclones are more baroclinic during the WAMO. This result is consistent with the meridional SST anomalous gradients between the bands north and south of the $40^{\circ} \mathrm{S}$, which are northward directed during the WAMO and southward directed during the CAMO (Fig. 1). Thus, the SST mean state creates large-scale anomalous gradient favorable to increase the low-level cyclone baroclinicity during the WAMO in relation to the CAMO.

The maps of the barotropic conversion term of the Lorenz energy cycle $\left(K_{l} K_{h}\right)$ are depicted in Fig. 9. The significant negative values of this energy conversion term, and thus reductions of the kinetic energy of the short waves and increases of the kinetic energy of the long waves, are noted in most of the study domain south of $50^{\circ} \mathrm{S}$ during both seasons and both AMO phases. This barotropic energy conversion is stronger in the WAMO than in the CAMO. On the other hand, conversion of $K_{l}$ into $K_{h}$ occurs in several bands, whose location depends on the season and AMO phases. Positive $K_{l} K_{h}$ values are noted in most of the band extending southeastward from the $30^{\circ}-40^{\circ} \mathrm{S}$, $160^{\circ}-120^{\circ} \mathrm{W}$ area into the central South Atlantic between $20^{\circ} \mathrm{W}$ and $0^{\circ}$ longitude and between $45^{\circ}$ and $55^{\circ} \mathrm{S}$ during summer and between $50^{\circ}$ and $60^{\circ} \mathrm{S}$ during winter (Fig. 9). The positive $K_{l} K_{h}$ values are not well defined during summer in the WAMO in the southeastern Pacific (Fig. 9a). During winter in both AMO phases, another almost zonal band between $25^{\circ}$ and $45^{\circ} \mathrm{S}$ and between $100^{\circ} \mathrm{W}$ and $0^{\circ}$ is evident (Figs. 9c,d). In this case, the barotropic conversion is stronger in the CAMO than in the WAMO. 
(a) WAMO DJF (Baroclinic Term)

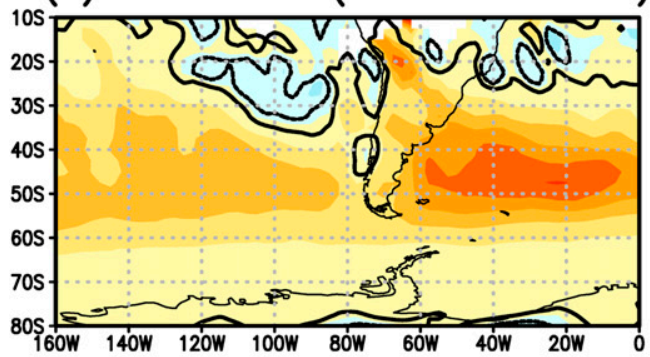

(b) CAMO DJF (Baroclinic Term)

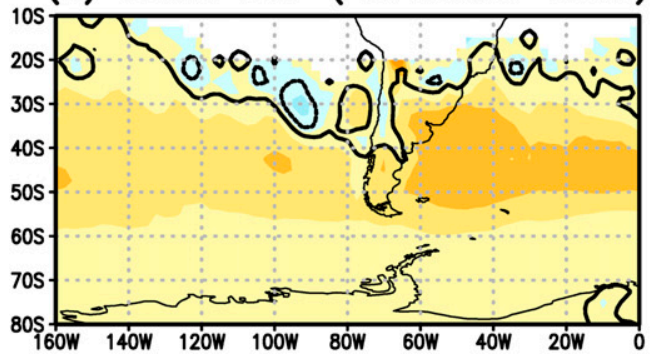

(c) WAMO JJA (Baroclinic Term)

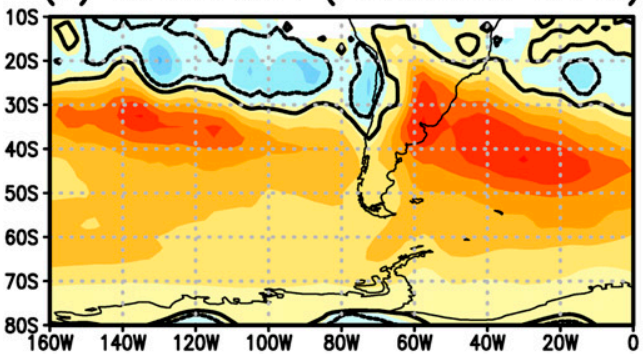

(d) CAMO JJA (Baroclinic Term)
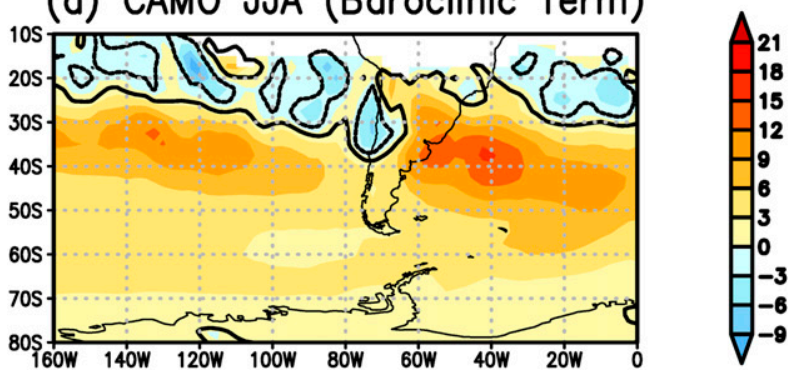

FIG. 8. Baroclinic conversion of energy $\left(\mathrm{W} \mathrm{m}^{-2}\right)$ during summer in the (a) WAMO and (b) CAMO and during winter in the (c) WAMO and (d) CAMO. The continuous (dashed) line encompasses positive (negative) significant values at the $95 \%$ confidence level using the Student's $t$ test.

\section{Discussion and conclusions}

This study investigated the hypothesis that the anomalous SST mean state associated with the AMO might alter the low-level cyclone features in the southeastern Pacific and South Atlantic using 39 years (1979-2017) of (a) WAMO DJF (Barotropic Term)
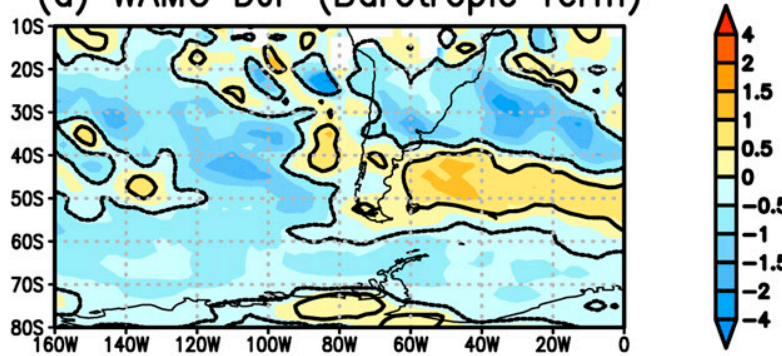

(b) CAMO DJF (Barotropic Term)
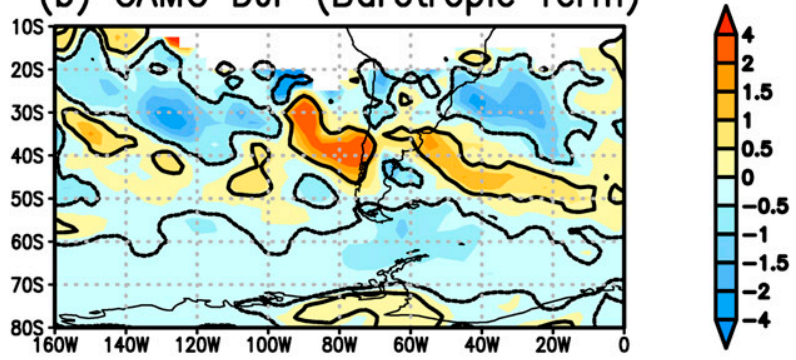

(c) WAMO JJA (Barotropic Term)

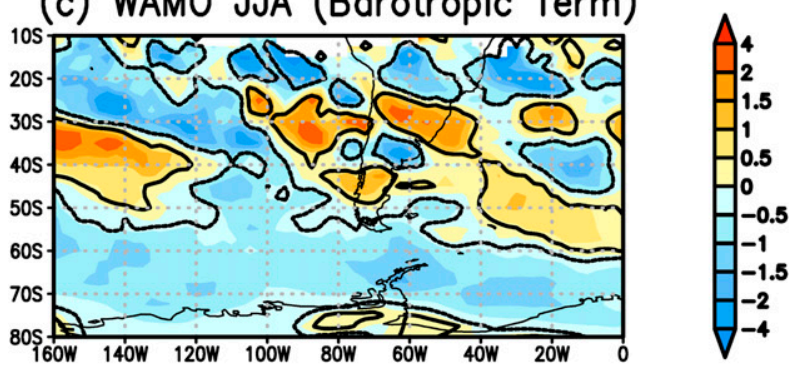

(d) CAMO JJA (Barotropic Term)

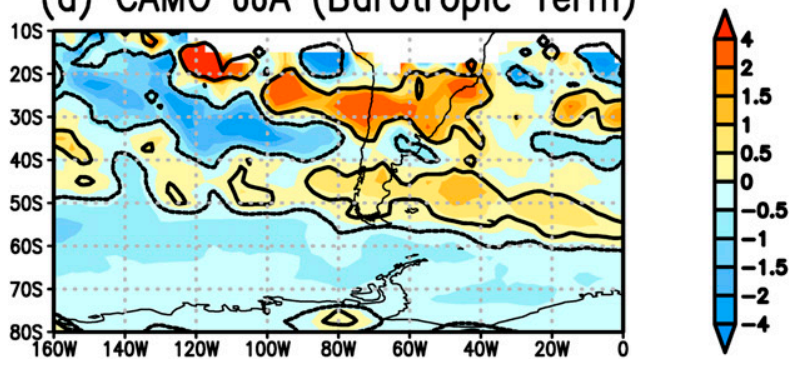

FIG. 9. Barotropic conversion of energy $\left(\mathrm{W} \mathrm{m}^{-2}\right)$ during summer in the (a) WAMO and (b) CAMO and during winter in the (c) WAMO and (d) CAMO. The continuous (dashed) line encompasses positive (negative) significant values at the $95 \%$ confidence level using the Student's $t$ test.

6-hourly NCEP-DOE Reanalysis II (Kanamitsu et al. 2002) data. This period contains two 15 -yr periods, 197993 and 2003-17, which overlap the CAMO and WAMO phases respectively. To show that these periods represent the two AMO phases, we used the monthly mean SST data from the extended reconstructed SST version 5 data 
for the 1870-2017 period (Huang et al. 2015). In this case, we removed the SST linear trends for the 1870-2017 period and the SST anomalies were based on the 19792017 base period. So, these anomalies do not contain the climate change trends. Also, an automatic cyclone tracking algorithm was used to identify the $925-\mathrm{hPa} c y-$ clones per grid box. We limited our study to the $20^{\circ}-75^{\circ} \mathrm{S}$, $160^{\circ}-0^{\circ} \mathrm{W}$ area, whose southern portion presents multidecadal SST variability modulated by the AMO (Folland et al. 1999; Timmermann et al. 2007).

The summer and winter SST anomaly maps during the 1979-93 and 2003-17 periods reproduced, respectively, the typical patterns previously documented as the CAMO and WAMO phases (Enfield and Mestas-Nuñez 1999; Folland et al. 1999; Mestas-Nuñez and Enfield 2001; Enfield et al. 2001; Timmermann et al. 2007). These patterns show large-scale meridional SST anomalous gradients between the bands north and south of $40^{\circ} \mathrm{S}$, which are northward directed in the WAMO and southward directed in the CAMO. The AMOrelated large-scale SST anomaly patterns play an important role in the cyclone trajectories and in the Lorenz energy cycle.

The positive SST anomalies of the mean state define approximately the cyclone trajectories, which vary seasonally and with the AMO phases. Indeed, the number of grid boxes with cyclone local counts exceeding 10 events during summer along the high midlatitudes is higher in the CAMO due to the positive SST anomalies in these latitudes compared to negative ones in the WAMO (Figs. 1a,b and 4a,b). During winter in the WAMO, the cyclone local counts exceeding 10 events per grid box along $40^{\circ} \mathrm{S}$ in the southeast Pacific and along $50^{\circ} \mathrm{S}$ in the South Atlantic occur approximately in the areas with positive SST anomalies (Figs. 1c and 4c). During winter in the CAMO the maximum cyclone local counts along $68^{\circ} \mathrm{S}$ in the Bellingshausen Sea are driven by the positive SST anomalies in the circumpolar and high middle latitudes in the southeastern Pacific (Figs. 1d and 4d). We also found that the cyclone densities in most latitudes during both seasons are higher in the CAMO than in the WAMO (Fig. 5). Therefore, considering the 1979-2017 period, the cyclone density in the study domain presents a reduction trend. Consistently, Simmonds and Keay (2000a) documented a decrease trend in the annual average number of cyclones in the $30^{\circ}-70^{\circ} \mathrm{S}$ band from 1970 to 1997 .

The large-scale northward SST anomalous gradients between the bands north and south of $40^{\circ} \mathrm{S}$ increase the baroclinicity in the midlatitudes in the WAMO, and the southward SST anomalous gradients decrease it in the CAMO. Our analysis refers to the low-frequency SST variations, so the SST meridional gradients alter the long-wave baroclinicity, which in turn takes part in the Lorenz energy cycle. Consistent with the AMO-related increased long-wave baroclinicity during both seasons, increased short-wave baroclinicity occurs in the WAMO compared to the CAMO (Fig. 8). Meanwhile, in the South Atlantic region off the Argentinean coast, both the barotropic and baroclinic conversion terms are positive, indicating increase of the kinetic energy of the short waves (Figs. 8 and 9). This is a known cyclogenetic region (Sinclair 1995, 1997).

Our results indicated higher cyclone densities in the CAMO than in the WAMO in most latitudes during both seasons (Fig. 5). However, the cyclones are more energetic during the WAMO than in the CAMO (Figs. 6-9). These distinct aspects of the low-level cyclones in the southeastern Pacific and South Atlantic during the two AMO phases are modulated by the AMO-related SST anomalies, with the positive anomalies affecting the cyclone trajectories and the meridional SST gradients affecting the baroclinicity of the long waves, which in turn enters in the energy Lorenz cycle.

Although the linear trends were removed from the SST data, this procedure does not completely remove the climate change signal. Nevertheless, the best estimate of the natural component of the AMO is the removal of the model-based estimates of the forced component variability (Ting et al. 2009; Frankcombe et al. 2015; Frankignoul et al. 2017). Since analysis with modeling outputs is out of the scope of the present study, we used Frankignoul et al.'s (2017) results to support the hypothesis that the SST patterns during the two selected periods contain the AMO signal. Their Fig. 8 shows the mean AMO pattern obtained after removing the anthropogenic effect from modeling estimates. Their "true" AMO pattern shows opposite-signed SST anomalies in the North Atlantic and the southern middle and high latitudes. This pattern is similar to that shown in our Fig. 1. Thus, Fig. 1 contains the AMOrelated variability, which might be intensified due to global change. However, this anthropogenic component does not invalidate our conclusions.

Our analysis clearly illustrates the relations of the lowlevel extratropical cyclones in the study domain to the AMO phases. As far as we know, these relations have not been examined before. However, the cyclonerelated changes described here might also be partially caused by the global warming between the two analyzed periods. The results here might be relevant to future diagnostic and modeling studies on the SH low-level extratropical cyclones. Finally, we are aware that the approach adopted here considering two $15-\mathrm{yr}$ periods as representative of the two AMO phases should be 
validated with a longer-period data. Such validation analysis is the subject of a future study by the authors.

Acknowledgments. The Conselho Nacional de Desenvolvimento Científico e Tecnológico (CNPq) of Brazil partially supported the first author under Grant 302322/2017-5. The authors thank the three anonymous reviewers for their useful comments and suggestions.

\section{REFERENCES}

Befort, D. J., S. Wild, T. Kruschke, U. Ulbrich, and G. C. Leckebusch, 2016: Different long-term trends of extra-tropical cyclones and windstorms in ERA-20C and NOAA-20CR reanalyses. Atmos. Sci. Lett., 17, 586-595, https://doi.org/10.1002/asl.694.

Blackmon, M. L., 1976: A climatological spectral study of the $500 \mathrm{mb}$ geopotential height of the Northern Hemisphere. J. Atmos. Sci., 33, 1607-1623, https://doi.org/10.1175/15200469(1976)033<1607:ACSSOT>2.0.CO;2.

Crowley, T. J., and K.-Y. Kim, 1993: Towards development of a strategy for determining the origin of decadal-centennial scale climate variability. Quat. Sci. Rev., 12, 375-385, https://doi.org/ 10.1016/S0277-3791(05)80003-4.

Delworth, T. L., and M. E. Mann, 2000: Observed and simulated multidecadal variability in the Northern Hemisphere 2000. Climate Dyn., 16, 661-676, https://doi.org/10.1007/s003820000075.

Eichler, T. P., and J. Gottschalck, 2013: A comparison of Southern Hemisphere cyclone track climatology and interannual variability in coarse-gridded reanalysis datasets. Adv. Meteor. 2013, 891260, https://doi.org/10.1155/2013/891260.

Enfield, D. B., and A. Mestas-Nuñez, 1999: Multiscale variabilities in global sea surface temperatures and their relationships with tropospheric climate patterns. J. Climate, 12, 2719-2733, https:// doi.org/10.1175/1520-0442(1999)012<2719:MVIGSS >2.0.CO;2.

_,- , and P. J. Trimple, 2001: The Atlantic multidecadal oscillations and its relation to rainfall and river flows in the continental U.S. Geophys. Res. Lett., 28, 2077-2080, https:// doi.org/10.1029/2000GL012745.

Folland, C. K., D. E. Parker, A. W. Colman, and R. Washington, 1999: Large-scale modes of ocean surface temperature since the late nineteenth century. Beyond El Niño: Decadal and Interdecadal Climate Variability, 1st ed., A. Navarra, Ed., Springer-Verlag, 73-102.

Frankcombe, L. M., M. H. England, M. E. Mann, and B. A Steinman, 2015: Separating internal variability from the externally forced climate response. J. Climate, 28, 8184-8202, https://doi.org/10.1175/JCLI-D-15-0069.1.

Frankignoul, C., G. Gastineau, and Y. O. Kwon, 2017: Estimation of the SST response to anthropogenic and external forcing and its impact on the Atlantic multidecadal oscillation and the Pacific decadal oscillation. J. Climate, 30, 9871-9895, https:// doi.org/10.1175/JCLI-D-17-0009.1.

Gan, M. A., and V. B. Rao, 1999: Energetics of the high frequency disturbances over South America. Rev. Bras. Geofis., 17, $21-$ 28, https://doi.org/10.1590/s0102-261x1999000100003.

Goldenberg, S. B., C. W. Landsea, A. M. Mestas-Nuñez, and W. M. Gray, 2001: The recent increase in Atlantic hurricane activity: Causes and implications. Science, 293, 474-479, https://doi.org/ 10.1126/science. 1060040.

Gómara, I., B. Rodríguez-Fonseca, P. Zurita-Gotor, S. Ulbrich, and J. G. Pinto, 2016: Abrupt transitions in the NAO control of explosive North Atlantic cyclone development. Climate Dyn., 47, 3091-3111, https://doi.org/10.1007/s00382-016-3015-9.

Grieger, J., G. C. Leckebusch, C. C. Raible, I. Rudeva, and I. Simmonds, 2018: Subantarctic cyclones identified by 14 tracking methods, and their role for moisture transports into the continent. Tellus, $\mathbf{7 0 A}, 1-18$, https://doi.org/10.1080/ 16000870.2018.1454808.

Hodges, K. I., 1994: A general-method for tracking analysis and its application to meteorological data. Mon. Wea. Rev., 122, 2573-2586, https://doi.org/10.1175/1520-0493(1994)122<2573: AGMFTA $>2.0 . \mathrm{CO} ; 2$.

Huang, B., and Coauthors, 2015: Extended reconstructed sea surface temperature version 4 (ERSST.v4). Part I: Upgrades and intercomparisons. J. Climate, 28, 911-930, https://doi.org/ 10.1175/JCLI-D-14-00006.1.

Jones, D. A., and I. Simmonds, 1993: Climatology of Southern Hemisphere extratropical cyclones. Climate Dyn., 9, 131-145, https://doi.org/10.1007/BF00209750.

Kanamitsu, M., W. Ebisuzaki, J. Woollen, S.-K. Yang, J. J. Hnilo, M. Fiorino, and G. L. Potter, 2002: NCEP-DOE AMIP-II Reanalysis (R-2). Bull. Amer. Meteor. Soc., 83, 1631-1643, https://doi.org/10.1175/BAMS-83-11-1631.

Kerr, R. A., 2000: A North Atlantic climate pacemaker for the centuries. Science, 288, 1984-1986, https://doi.org/10.1126/ science.288.5473.1984.

Knight, J. R., C. K. Folland, and A. A. Scaife, 2006: Climate impacts of the Atlantic multidecadal oscillation. Geophys. Res. Lett., 33, L17706, https://doi.org/10.1029/2006GL026242.

Mantua, N. J., S. R. Hare, Y. Zhang, J. M. Wallace, and R. C. Francis, 1997: A Pacific interdecadal climate oscillation with impacts on salmon production. Bull. Amer. Meteor. Soc., 78, 1069-1079, https://doi.org/10.1175/1520-0477(1997)078<1069: APICOW $>2.0 . C O ; 2$

Mendes, D., E. P. Souza, J. A. Marengo, and M. C. D. Mendes, 2010: Climatology of extratropical cyclones over the South American-southern oceans sector. Theor. Appl. Climatol., 100, 239-250, https://doi.org/10.1007/s00704-009-0161-6.

Mestas-Nuñez, A. M., and D. B. Enfield, 2001: Eastern equatorial Pacific SST variability: ENSO and non-ENSO components and their climate associations. J. Climate, 14, 391-402, https://doi.org/10.1175/1520-0442(2001)014<0391: EEPSVE $>2.0 . \mathrm{CO} ; 2$.

Neu, U., and Coauthors, 2013: IMILAST: A community effort to intercompare extratropical cyclone detection and tracking algorithms. Bull. Amer. Meteor. Soc., 94, 529-547, https:// doi.org/10.1175/BAMS-D-11-00154.1.

Orlanski, I., 1975: A rational subdivision of scales for atmospheric processes. Bull. Amer. Meteor. Soc., 56, 527-530, https:// doi.org/10.1175/1520-0477-56.5.527.

- and J. Katzfey, 1991: The life cycle of a cyclone wave in the Southern Hemisphere. Part I: Eddy energy budget. J. Atmos. Sci., 48, 1972-1998, https://doi.org/10.1175/1520-0469(1991) 048<1972:TLCOAC $>2.0$. CO;2.

Parker, D. E., P. D. Jones, C. K. Folland, and A. Bevan, 1994 : Interdecadal changes of surface temperature since the late nineteenth century. J. Geophys. Res., 99, 14373-14399, https://doi.org/10.1029/94JD00548.

Peixoto, J. P., and A. H. Oort, 1992: Physics of Climate. MIT Press, 520 pp.

Pinto, J. R. D., and R. P. Rocha, 2011: The energy cycle and structural evolution of cyclones over southeastern South America in three case studies. J. Geophys. Res., 116, D14112, https://doi.org/10.1029/2011JD016217. 
Reason, C. J. C., 2000: Multidecadal climate variability in the subtropics/mid-latitudes of the Southern Hemisphere oceans. Tellus, 52A, 203-223, https://doi.org/10.1034/j.1600-0870. 2000.00978.x.

_ , and R. J. Murray, 2001: Modelling low frequency variability in Southern Hemisphere extra-tropical cyclone characteristics and its sensitivity to sea-surface temperature. Int. J. Climatol., 21, 249-267, https://doi.org/10.1002/joc.608.

Reboita, M. S., R. P. da Rocha, T. Ambrizzi, and C. D. Gouveia, 2015: Trend and teleconnection patterns in the climatology of extratropical cyclones over the Southern Hemisphere. Climate Dyn., 45, 1929-1944, https://doi.org/10.1007/s00382-014-2447-3.

Rosa, M. B., N. J. Ferreira, M. A. Gan, and L. H. R. Machado, 2013: Energetics of cyclogenesis events over the southern coast of Brazil. Rev. Bras. Meteor., 28, 231-245, https://doi.org/10.1590/ S0102-77862013000300001.

Schlesinger, M. E., and N. Ramankutty, 1994: An oscillation in the global climate system of period 65-70 years. Nature, 367, 723726, https://doi.org/10.1038/367723a0.

Schneider, D. P., and R. L. Fogt, 2018: Artifacts in century-length atmospheric and coupled reanalyses over Antarctica due to historical data availability. Geophys. Res. Lett., 45, 964-973, https://doi.org/10.1002/2017GL076226.

Simmonds, I., and K. Keay, 2000a: Variability of Southern Hemisphere extratropical cyclone behavior, 1958-97. J. Climate, 13, 550-561, https://doi.org/10.1175/1520-0442(2000)013<0550: VOSHEC $>2.0 . \mathrm{CO} ; 2$.

— cyclone behavior in the 40-year NCEP-NCAR reanalysis. J. Climate, 13, 873-885, https://doi.org/10.1175/1520-0442(2000) 013<0873:MSHECB > 2.0.CO;2.

Sinclair, M. R., 1994: An objective cyclone climatology for the Southern Hemisphere. Mon. Wea. Rev., 122, 2239-2256, https://doi.org/ 10.1175/1520-0493(1994)122<2239:AOCCFT>2.0.CO;2.
1995: A climatology of cyclogenesis for the Southern Hemisphere. Mon. Wea. Rev., 123, 1601-1619, https://doi.org/ 10.1175/1520-0493(1995)123<1601:ACOCFT>2.0.CO;2.

_ 1997: Objective identification of cyclones and their circulation intensity, and climatology. Wea. Forecasting, $\mathbf{1 2}$ 595-612, https://doi.org/10.1175/1520-0434(1997)012<0595: OIOCAT $>2.0 . \mathrm{CO} ; 2$.

Timmermann, A., and Coauthors, 2007: The influence of a weakening of the Atlantic meridional overturning circulation on ENSO. J. Climate, 20, 4899-4919, https://doi.org/10.1175/ JCLI4283.1.

Ting, M., Y. Kushnir, R. Seager, and C. Li, 2009: Forced and internal twentieth-century SST trends in the North Atlantic. J. Climate, 22, 1469-1481, https://doi.org/10.1175/2008JCLI2561.1.

Varino, F., P. Arbogast, B. Joly, G. Riviere, M.-L. Fandeur, H. Bovy, and J.-B. Granier, 2018: Northern Hemisphere extratropical winter cyclones variability over the 20th century derived from ERA-20C reanalysis. Climate Dyn., 52, 10271048, https://doi.org/10.1007/s00382-018-4176-5.

Venegas, S. A., L. A. Mysak, and D. N. Straub, 1996: Evidence for interannual and interdecadal climate variability in the South Atlantic. Geophys. Res. Lett., 23, 2673-2676, https://doi.org/ 10.1029/96GL02373.

_ — , and - 1998: An interdecadal climate cycle in the South Atlantic and its links to other ocean basins. J. Geophys. Res., 103, 24 723-24 736, https://doi.org/10.1029/98JC02443.

Wang, X. L., Y. Feng, G. P. Compo, V. R. Swail, F. W. Zwiers, R. J. Allan, and P. D. Sardeshmukh, 2013: Trends and low frequency variability of extra-tropical cyclone activity in the ensemble of twentieth century reanalysis. Climate Dyn., $\mathbf{4 0}$, 2775-2800, https://doi.org/10.1007/s00382-012-1450-9.

Zhang, Y., J. M. Wallace, and D. Battisti, 1997: ENSO-like interdecadal variability: 1900-93. J. Climate, 10, 1004-1020, https:// doi.org/10.1175/1520-0442(1997)010<1004:ELIV>2.0.CO;2. 